\title{
A coordenação pedagógica faz diferença: As práticas de sucesso na alfabetização em território vulnerável ${ }^{1}$
}

\author{
Pedagogical coordination makes difference: \\ Successful literacy practices in vulnerable territory
}

Sandra Maria Perpétuo Mestre em Educação pela UFOP. Pedagoga analista e coordenadora de formação continuada da Secretaria Municipal de Educação de Governador Valadares-MG. Professora adjunta e coordenadora do curso de Pedagogia da Faculdade Presidente Antônio Carlos de Governador Valadares - MG. sandramariaperpetuo@gmail.com

\begin{abstract}
Rosa Maria da Exaltação Coutrim
Doutora em Ciências Humanas - Sociologia e Política pela UFMG e pós-doutora em Educação pelo Instituto Politécnico de Leiria, Portugal. Professora Associada do Departamento de Educação e da Pós-graduação em Educação da Universidade Federal de Ouro Preto. Pesquisadora do Núcleo de Estudos Sociedade, Família e Escola (NESFE-UFOP). rosacoutrim@ufop.edu.br
\end{abstract}

Resumo: Ao identificar casos de sucesso na alfabetização em território vulnerável e ancorada em estudos que mostram a influência do território vulnerável na aprendizagem dos alunos (BATISTA; CARVALHO-SILVA, 2013; CENPEC, 2011; ERNICA; 2012), esta pesquisa buscou responder à questão: quais fatores levam uma escola situada em território vulnerável a apresentar maior percentual de alunos no nível avançado em alfabetização nas provas do PROALFA. O método de pesquisa foi um estudo de caso, com análise documental, observação e entrevistas com profissionais da escola e familiares dos alunos. A unidade de estudo foi a Escola Municipal Professora Laura Fabri que, entre 19 escolas municipais de Governador Valadares-MG, apresentou melhor desempenho no PROALFA, entre 2014 e 2016. Dos cinco mecanismos que explicam as razões do sucesso da escola em alfabetização, nesse artigo, serão abordados os dois que colocam em evidência o efeito da atuação do pedagogo: coordenação das práticas de alfabetização e formação continuada.

Palavras-chave: Coordenação Pedagógica. Território Vulnerável. Efeito Escola. Sucesso em Alfabetização.

Abstract: In this paper, we present the results of a study on the impact of vulnerable territory on students' learning (BATISTA, CARVALHO-SILVA, 2013, CENPEC, 2011, ERNICA, 2012) what factors lead a school located in vulnerable territory to present a higher percentage of students at the advanced literacy level in the PROALFA tests. The research method was a case study, with documentary analysis, observation and interviews with school professionals and students' families. The study unit was the Municipal School Professor Laura Fabri, who, among 19 municipal schools in Governador Valadares-MG, presented a better performance in PROALFA between 2014 and 2016. Of the five mechanisms that explain the reasons for the success of the school in literacy, in this article, the two that highlight the effect of the pedagogue's performance will be addressed: coordination of literacy practices and continuing education.

Key-words: Pedagogical Coordination. Vulnerable Territory. School Effect. Success in Literacy.

\footnotetext{
${ }^{1}$ Este artigo é um recorte da dissertação Alfabetização em território vulnerável: o caso de sucesso da Escola Municipal Professora Laura Fabri, em Governador Valadares-MG, realizada no Programa de Pós - graduação em Educação - Mestrado da Universidade Federal de Ouro Preto, e defendida em 18 de fevereiro de 2019.
} 


\section{Introdução}

Escolas situadas em território vulnerável enfrentam grandes problemas de ordem social, econômica e cultural. Nesses espaços, há menor de oferta de serviços públicos e privados, maior concentração de população com baixo nível socioeconômico e cultural, e acentuada rotatividade de professores. Como já vem sendo evidenciado nos estudos desenvolvidos por Batista e Carvalho-Silva (2013), pelo CENPEC (2011) e por Ernica (2012), o contexto socioeconômico e o baixo capital cultural das famílias que vivem em território vulnerável podem impactar negativamente na aprendizagem dos alunos.

No entanto, existem outros fatores que influenciam no desempenho escolar das crianças e dos jovens. Pesquisas nacionais e internacionais sobre eficácia escolar e eficácia docente demonstram que, apesar dos aspectos socioeconômicos e culturais das famílias exercerem forte influência nos resultados da aprendizagem, a escola em que o aluno estuda também faz diferença em seu desempenho escolar (BROOKE; SOARES, 2008; MADAUS et al.,1980; MORTIMORE et al.,1988; RUT'TER et al., 1979).

A eficácia refere-se à qualidade das instituições de ensino, à produção de resultados que a sociedade espera delas (MADAUS et al., 1980) e é também compreendida como a capacidade de as escolas influenciarem no desenvolvimento dos alunos (TORRECILLA, 2003). Já a ineficácia é compreendida, por Coleman (1966), como a incapacidade de as escolas removerem o impacto que as influências externas exercem sobre o desempenho escolar.

A pesquisa aqui apresentada ancorou-se nesta discussão a respeito da eficácia escolar e da influência do território no desempenho escolar do aluno para discutir um caso específico encontrado em uma cidade do interior de Minas Gerais. Em um universo de 19 escolas do perímetro urbano que atendem as classes de alfabetização no município de Governador Valadares-MG, buscou-se encontrar aquela com maior percentual de alunos no nível avançado em alfabetização nas provas do Programa de Avaliação da Alfabetização (PROALFA), no período de 2014 a 2016. Identificou-se que a Escola Municipal Professora Laura Fabri, situada em território vulnerável, era a que apresentava melhor resultado na avaliação. $O$ encontro inesperado dessa escola provocou inquietações a respeito das estratégias adotadas pela equipe gestora para obter o sucesso diante de condições adversas. Para realização do estudo, o projeto de pesquisa foi aprovado pelo Comitê de Ética da UFOP e, mediante autorização da Secretaria Municipal de Educação de Governador Valadares e dos participantes da investigação, o uso e a divulgação do nome da escola e dos depoentes foram citados no artigo. 
Assim, tal escola passou a ser analisada com o objetivo de compreender os fatores associados ao seu desempenho positivo no PROALFA. Tais resultados tornaram a escola diferenciada, conforme o conceito de escola eficaz trazido pela literatura (BROOKE; SOARES 2008), que indica que algumas escolas, considerando o Nível Sócio Econômico (NSE) dos alunos e as condições estruturais, são melhores que as outras.

Assim, lançando mão dos resultados do PROALFA foi definida a questão central da pesquisa: quais fatores levam uma escola situada em território vulnerável a apresentar maior percentual de alunos no nível avançado em alfabetização nas provas do PROALFA?

O procedimento metodológico adotado para a realização desta pesquisa qualitativa foi um estudo de caso. Para identificar os fatores que ajudam a explicar as razões do sucesso em alfabetização da escola definida como unidade de estudo, além da observação das práticas educativas, foram realizadas entrevistas semiestruturadas com a diretora, a pedagoga e três professoras que atuaram nos três primeiros anos do Ensino Fundamental no período em que as provas foram aplicadas. Do quantitativo de 34 famílias de alunos que tiveram desempenho classificado como avançado pelo PROALFA, cinco foram selecionadas para as entrevistas, realizadas em suas residências, quando também foram observadas suas dinâmicas e a organização dos espaços.

Ao longo da pesquisa foram encontrados cinco mecanismos que ajudaram a compreender as razões do sucesso na alfabetização da Escola Municipal Professora Laura Fabri: a atuação dos profissionais na escola, sob a coordenação da pedagoga, que ameniza o impacto da vulnerabilidade do território e da infraestrutura precária; a formação continuada desenvolvida pela pedagoga na escola, que atua como uma forte estratégia em relação à rotatividade de professores; a experiência de algumas professoras nas classes de alfabetização e sua atuação no último ano do ciclo de alfabetização; a alfabetização por meio de distintos métodos e sua adequação aos diferentes estilos de professores e às aprendizagens dos alunos; e as estratégias de intervenção pedagógica que envolvem o trabalho com as crianças e as famílias.

Este artigo propôs discutir dois desses mecanismos: a atuação dos profissionais na escola, sob a coordenação da pedagoga, e a formação continuada dos professores desenvolvida por ela.

\section{A coordenação das práticas de alfabetização da Escola Municipal Professora Laura Fabri}

A Escola Municipal Professora Laura Fabri tem 834 estudantes, com 85 crianças de 0 a 3 anos na creche, 109 de 4 a 5 anos na Educação Infantil, e 640 alunos do $1^{\circ}$ ao $9^{\circ}$ ano do Ensino Fundamental. 
Para atendimento desta demanda, a instituição conta com 127 funcionários. Destes, 16 são professores regentes de turma nos Anos Iniciais do Ensino Fundamental, dois são professores eventuais e quatro são regentes de aulas de Inglês, Educação Física, Dança e de Xadrez. Os demais são professores da Educação Infantil, dos Anos Finais do Ensino Fundamental, monitores de turma e de Educação Inclusiva, assistentes de turno e auxiliares de serviço público.

A instituição funciona em tempo integral, desde 2010, no período das $7 \mathrm{~h}$ às $15 \mathrm{~h}$. Atualmente, na sede da escola, são atendidas 16 turmas: quatro de $1^{\circ}$ ano; três do $2^{\circ}$; cinco de $3^{\circ}$; duas do $4^{\circ}$; e duas do $5^{\circ}$ ano do Ensino Fundamental. Vale ressaltar que as crianças que fizeram o PROALFA em 2016, hoje, estudam no $5^{\circ}$ ano. Até 2015, esses alunos estudavam em um dos prédios anexos da escola.

Todas as professoras que atuam na regência dos Anos Iniciais dessa escola trabalham com uma carga horária de 40 horas. Destas, 25 horas são destinadas à regência, seis para estudos individuais e coletivos; quatro para pequenos intervalos e descanso; três para estudo entre os pares; e duas horas para atividades extraclasse, que são cumpridas pelos professores nos locais que melhor atenderem às suas conveniências (GOVERNADOR VALADARES, 2009).

A coordenação dos trabalhos das classes de alfabetização da Escola Municipal Professora Laura Fabri é feita pela pedagoga Márcia Cândida há 10 anos. Ela é graduada em Pedagogia e pós-graduada em Planejamento Educacional. Tem 60 anos, é parda e atua há 41 anos em escolas públicas da periferia. Aposentou-se como professora da rede estadual depois de 32 anos de serviço. Destes, atuou durante 21 anos como professora em classes de alfabetização e 11 anos na vice-direção. Nas escolas da Secretaria Municipal de Educação de Governador ValadaresMG, atua como pedagoga há 30 anos e já possui tempo para se aposentar. No momento da realização da pesquisa de campo, coordenava o trabalho de 15 turmas do $1^{\circ}$ ao $5^{\circ}$ ano dos Anos Iniciais do Ensino Fundamental, que possuíam, ao todo, 480 alunos. Sob a sua coordenação, tem 16 professores regentes de turma e seis regentes de aula.

Por meio da pesquisa de observação e dos relatos das professoras e da pedagoga, foi possível conhecer a rotina de trabalho desenvolvida em sala de aula e o contexto em que a escola investigada está inserida. Como as professoras têm nove horas semanais destinadas a estudos e ao planejamento das aulas, a pedagoga realiza formações em pequenos grupos, durante três horas semanais, e faz atendimentos individualizados para analisar as propostas de trabalhos elaboradas por elas, para encaminhar novas práticas, analisar as produções de textos dos alunos, as provas e outros instrumentos de avaliação aplicados. O estudo é organizado de acordo com o ano de atuação das professoras: do $1^{\circ}$ ao $5^{\circ}$ ano do Ensino Fundamental. Durante o tempo em que a 
pedagoga está realizando algum tipo de formação com as professoras regentes de turma, as crianças estudam com professores de componentes específicos. A esses professores também é reservado um horário para atendimento individualizado.

Quando foram observadas as práticas das professoras do $1^{\circ}, 2^{\circ}$ e $3^{\circ}$ anos, constatou-se que havia uma uniformidade nas ações, com aplicação dos mesmos conteúdos, recursos e práticas orientadas pela pedagoga nos estudos. Isto é, havia uma coerência entre as ações de sala de aula e da coordenação pedagógica.

Em seu depoimento, a pedagoga afirma ser fundamental que sejam feitos planos de trabalhos integrados nas turmas. Nos momentos do estudo, ela compartilha os materiais e explica como usá-los. Também costuma ir às salas, especialmente das professoras novatas, para conferir como a atividade está sendo aplicada. Essa prática de visita às salas de aula é apontada, por Brooke e Soares (2008), como uma característica das escolas eficazes.

Para maior controle da gestão das aprendizagens dos alunos, a pedagoga, além de elaborar sequências de atividades para serem aplicadas em todas, também elabora as provas de Língua Portuguesa e de Matemática do $1^{\circ}$ ao $5^{\circ}$ ano. Ao ser questionada sobre as razões que a levavam a elaborar as provas, disse que era uma forma de garantir a qualidade do instrumento:

Porque tem 16 professores do $1^{\circ}$ ano ao $5^{\circ}$ ano, só tem quatro computadores disponíveis e não considero que, com nove módulos aulas destinadas para estudo e planejamento, um professor tenha tempo o suficiente para elaborar provas de Língua Portuguesa, Matemática, História, Geografia, Ciências, Letramento e Arte (Márcia Cândida, pedagoga, 2018).

Ao demonstrar possuir conhecimento da rotina das professoras fora da escola, a pedagoga disse, ainda, que as professoras trabalham em regime de 40 horas e que o salário que um profissional da Educação recebe não garante condições de pagar alguém que faça os trabalhos domésticos. Então, ela reconhece que essas professoras, quando chegam em casa, têm obrigações que não permitem que se dediquem ao planejamento de atividades e provas.

O processo de organização do trabalho pedagógico é definido pela pedagoga com respeito aos modos de fazer dos professores, desde que associem suas práticas às novas metodologias aplicadas pela escola, especialmente as de ensino da leitura e da escrita. A forma incisiva de atuação da pedagoga é reconhecida na entrevista das três professoras, da diretora atual e de outros professores.

A professora Fabiana, que trabalha nas turmas do $3^{\circ}$ ano, disse que chegou à escola há oito anos, mas com um mês de experiência de trabalho em outra instituição da rede municipal e, comparando a pedagoga atual com a anterior, contou que não recebeu 
orientação nenhuma. Cheguei totalmente desorientada, não tinha nenhum norte e ninguém para chegar e falar: "Faz um diagnóstico para ver como a sua turma está". O básico, que é esse diagnóstico que a gente faz da turma para a gente conhecer: observa, toma leitura, anota. Isso aí eu não tive na outra escola. [...] Ficava perdida. Então, não tive orientação nenhuma. [...] Aí eu chegava para pedagoga e falava: "Pedagoga, pedagoga de Deus, o que é que eu faço?” Parece que eles tinham pegado todos os meninos com dificuldade e colocado ali. Aí ela falava assim: "Ah, tenho uma atividade aqui”. Uma atividade impressa que já estava apagando assim. Então, isso é orientação pedagógica? (Fabiana, professora, 2018).

Para a professora Fabiana, os resultados positivos da escola são fruto de um trabalho coletivo, mas especialmente da atuação da pedagoga. A contribuição do trabalho da pedagoga nos resultados da escola também é citada nas entrevistas de todos os profissionais. A diretora, apesar de ter assumido a direção em 2017, trabalhava na escola desde 2010 como professora de Educação Física e considera que o sucesso da escola é resultado de um esforço coletivo, mas enfatiza que a maior contribuição foi da pedagoga, seguida da atuação dos professores e da diretora da época.

Embora todas as profissionais da escola destaquem os efeitos do trabalho da pedagoga nos resultados da escola, há também, por parte dela, um reconhecimento do esforço coletivo da equipe, para o desempenho da escola em alfabetização, pois considera que o resultado é fruto de:

\footnotetext{
Muito estudo. Muita observância ao que determinam os PCNs. Ação, reflexão, ação. Muita prática comum no grupo. A disponibilidade das intervenções pedagógicas, em que os agrupamentos temporários são feitos sem ferir egos. Por exemplo, quem sabe mais trabalha com os meninos que sabem menos. Troca de experiência. Compromisso do professor com a pontualidade, com a assiduidade. $\mathrm{O}$ aprofundamento nas questões práticas. A credibilidade que a escola foi construindo com a comunidade. E essa credibilidade resulta no ouvir o texto do caderno de leitura que o aluno leva para ler em casa, isso ajuda muito. Mas, sobretudo, o arregaçar as mangas dos professores, porque eles abriram mão, em muitas situações, por conta própria, da sua janela [horários vagos] para sentar do lado de fora para ajudar alunos com maiores dificuldades. Outra coisa que é fundamental, é que não tem só o professor regente, todo mundo que está na escola é responsável por aquele aluno. Aqui todos os professores participam juntos (Márcia Cândida, pedagoga, 2018).
}

Este comprometimento dos professores com a aprendizagem dos alunos, os estudos realizados e o fato do corpo docente, dos gestores e dos funcionários da escola demonstrarem ter consciência da visão e da missão compartilhada pela equipe também correspondem a algumas características comuns de escolas mais eficazes (BROOKOVER et al., 1978; MORTIMORE et al., 1988; RUTTER et al., 1979).

Para garantir um melhor desempenho dos alunos das classes de alfabetização nas provas externas, estrategicamente, a pedagoga relata que mantém no $3^{\circ}$ ano suas alfabetizadoras mais experientes e que são efetivas, pois, além das condições que possuem para desenvolverem um 
trabalho melhor, podem amenizar os prejuízos causados pela rotatividade de professores que, geralmente, faz com que as profissionais inexperientes assumam a regência no $1^{\circ}$ e $2^{\circ}$ anos.

Combinando diferentes estratégias para a superação das dificuldades de aprendizagens, as crianças que precisam são atendidas individualmente, com atividades diferenciadas, na própria sala ou em horários em que as professoras estão fora da regência.

\section{A formação continuada desenvolvida pela pedagoga na escola: uma estratégia eficaz}

Ao organizar os horários de estudo e planejamento dos professores, a pedagoga Márcia disse que sempre assegurou que os professores conseguissem se reunir com seus pares para troca de experiências. Esse tipo de medida adotada pela escola, em que os docentes formam uma comunidade de aprendizagem, é também identificado em pesquisas como uma prática das escolas eficazes (BROOKOVER et al., 1978; MORTIMORE et al., 1988; RUTTER et al., 1979). Também é importante observar que esse tipo de colaboração entre os docentes comprova o que havia sido evidenciado nas pesquisas nacionais, de que o trabalho colaborativo entre a equipe escolar, a responsabilidade dos docentes e o empenho coletivo se refletem sobre o desempenho dos alunos (ALVES; FRANCO, 2008).

A formação continuada é utilizada, pela pedagoga, como estratégia para enfrentamento dos problemas provenientes da formação e da prática das professoras. Ao receber um professor novato, ela sonda seus conhecimentos básicos, que deveriam ter sido aprendidos na faculdade, e esclarece:

\footnotetext{
Não me responda que sabe mais ou menos. Preciso saber o que você sabe ou não sabe para eu te ensinar. Eu não posso entregar meu filho para ser operado por um médico que sabe mais ou menos. Do mesmo modo, não posso confiar o filho de alguém para um professor que sabe mais ao menos (Márcia Cândida, pedagoga, 2018).
}

Essa sondagem que a pedagoga faz com os professores recém-chegados, segundo ela, é o ponto de partida para que inicie seu trabalho de formação e para que eles sejam capazes de ensinar as crianças.

Esse tipo de ação da pedagoga com os professores pode constituir um diferencial para os resultados da escola analisada em alfabetização, pois estudos internacionais (BROOKOVER et al., 1978; MORTIMORE et al., 1988; RUTTER et al., 1979) revelam que, em escolas eficazes, há uma formação de qualidade pautada na prática, e que os professores são capazes de planejar e executar bem as suas aulas.

Como a formação das professoras é por ano de atuação, a rotina de trabalho da pedagoga contempla três horas diárias de estudo com as docentes. Para Márcia, essa organização 
é importante porque as necessidades de formação das professoras e o material que precisam receber para trabalhar com as turmas são diferentes.

É inconcebível ensinar o professor do $1^{\circ}$ ano consciência fonológica, relação grafema fonema e, ao mesmo tempo, ensinar ao professor do $3^{\circ}$ ano a corrigir um texto já produzido pelo aluno. Os aspectos notacionais trabalhados no $1^{\circ}$ ano não são os mesmos aspectos notacionais trabalhados no $3^{\circ}$ ano (Márcia Cândida, pedagoga, 2018).

O conhecimento aplicado pela pedagoga sobre o processo de alfabetização de cada ano com suas especificidades é correlato ao que Soares (2018) chama de facetas. A primeira é a faceta linguística, que corresponde ao processo inicial da alfabetização, fase de apropriação do sistema alfabético-ortográfico e das convenções do sistema de escrita alfabético. Nesse primeiro momento, a pedagoga dá ênfase ao trabalho com a consciência fonológica. A segunda corresponde à faceta interativa, que consiste no desenvolvimento de habilidades para compreender e produzir textos. A terceira refere-se à faceta sociocultural, que corresponde à capacidade de interação em eventos sociais e culturais que exigem domínio de habilidades de leitura e escrita.

Para garantir essa tricotomia que envolve o processo de alfabetização (faceta linguística, interativa e sociocultural), Márcia tem selecionado uma professora mais experiente de cada ano para ser seu "carro chefe" e impulsionar o trabalho planejado.

Observou-se que a formação continuada é orientada para a prática em sala de aula, aspecto citado por Brookover et al. (1978); Mortimore et al. (1988) e Rutter et al. (1979), como característica comum das escolas eficazes. Em alguns momentos nos quais a pedagoga atendia individualmente as professoras, presenciou-se situações em que ela analisava as produções das crianças e explicava porque escreviam daquela forma, o que era preciso ensinar e como trabalhar para que superassem suas dificuldades.

Também foram observadas situações em que, após a análise das provas e das produções dos alunos, Márcia entregou, para as professoras, uma coletânea de textos para trabalharem a leitura com as crianças e mostrou como deveriam desenvolver as atividades. Essa também é mais uma característica comum entre as escolas eficazes, em que há um monitoramento das aprendizagens dos alunos e das atividades feitas na escola (BROOKOVER et al., 1978; MORTIMORE et al., 1988; RUTTER et al., 1979).

Nesse sentido, o trabalho feito por Márcia, direcionado para o $1^{\circ}$ ano, era orientado para o uso de textos menores, como cantigas populares. Em certo momento do trabalho de campo, verificou-se que, depois de pedir às professoras que escrevessem cartazes para trabalhar com as 
crianças, a pedagoga pediu que pintassem uma palavra de cada cor e mostrou como deveriam trabalhar com as crianças. Explicou que deveriam fazer leitura coletiva; que apontassem para cada palavra; que explorassem a característica do gênero estrofes e versos; que identificassem as rimas; e que observassem que cada palavra é separada por espaços. Ao finalizar, deveriam retirar palavras do texto para trabalhar a análise com as crianças, identificando as sílabas e as letras.

Ao observar uma prática de uma professora do $3^{\circ}$ ano, foi questionado como havia definido os procedimentos de ensino da leitura. Ela disse:

\begin{abstract}
Somos orientados pela nossa pedagoga. Ela nos ensina como devemos ensinar. Aprendemos muito com ela. Quando cheguei aqui, sofri muito. Meus olhos lacrimejavam porque tudo que eu fazia não conseguia corresponder ao que ela queria que eu fizesse. Tive vontade de sair porque já era professora há 10 anos e tudo que fazia era elogiado. Meu trabalho se destacava. Mas, valeu a pena ter ficado, hoje sei o que realmente deve ser ensinado na alfabetização e como dever ser ensinado (Sabrina, professora, 2018).
\end{abstract}

No relato dessa professora e também de outras encontram-se evidências de que a pedagoga trabalha a formação continuada, presente na Lei Complementar $n^{\circ}$. 129/2009 do município, que prevê, para professores com um regime de 40 horas, nove módulos destinados a estudos e planejamento.

Sobre os cuidados e a atenção especial com os professores novatos, foi observada uma situação em que a pedagoga permaneceu três horas ensinando o que a professora deveria dominar para alfabetizar as crianças. Com acesso autorizado ao caderno em que a professora fez as anotações sobre o que a pedagoga havia lhe ensinado, foi possível conhecer as concepções epistemológicas sobre o processo de alfabetização e letramento da escola investigada.

\begin{abstract}
Entende-se por alfabetização como o processo específico e indispensável de apropriação do sistema de escrita, a conquista dos princípios alfabéticos e ortográficos que possibilitam o aluno ler e escrever com autonomia. Letramento como o processo de inclusão e participação na cultura escrita (Professora anônima do $1^{\circ}$ ano, anotações, 2018).
\end{abstract}

Ao definir o conceito de alfabetização e letramento, a pedagoga evidencia a especificidade dos dois processos. Concepção defendida por Soares (2013), que destaca a importância de se considerar essa especificidade e a relação entre eles e sua indissociabilidade, mas sem desconsiderar os aspectos específicos que envolvem o ensino da alfabetização.

Nas anotações da professora novata, identificou-se também que, nas formações da pedagoga, havia uma prática orientada para o avanço dos níveis de escrita, com explicações detalhadas de como deveria trabalhar. 
As orientações feitas pela pedagoga mostram que sua prática é orientada para o ensino direto e explícito e que ela conjuga procedimentos fundamentos no paradigma construtivista e fonológico, prática defendida por Soares (2018). Isso porque, ao mesmo tempo que a pedagoga considerava o processo de evolução do sistema de escrita da criança (paradigma construtivista), ela orientava práticas de intervenção do sistema notacional (paradigma fonológico).

O modo como a pedagoga organiza e orienta a prática dos professores mostra aspectos que podem explicar os resultados positivos no PROALFA. Apesar da rotatividade e inexperiência de um considerável número de professores, há uma atenção especial à formação das professoras e uma prática metodológica de alfabetização bem definida. Como já mencionado, a qualidade da formação realizada na própria escola produz efeitos na aprendizagem (BROOKOVER et al., 1978; MORTIMORE et al., 1988; RUTTER et al., 1979) e a clara definição dos procedimentos adotados para alfabetizar, sustentados por uma base teórica, são aspectos que influenciam de forma positiva no processo de alfabetização (SOARES, 2018).

Por meio das ações desenvolvidas, mesmo estando em território vulnerável, a escola investigada apresentou o maior percentual de alunos no nível avançado em alfabetização, no período de 2014 a 2016. Essa evidência parece se contrapor a estudos que indicam haver influência da vulnerabilidade social e da rotatividade de professores na proficiência de aprendizagem dos alunos.

Das nove professoras que atuaram na instituição nos três primeiros anos do Ensino Fundamental, entre 2014 a 2016, apenas quatro continuam trabalhando na escola. As demais se aposentaram ou perderam o vínculo com a escola após encerramento do contrato. Comprovando as pesquisas desenvolvidas por Batista et al. (2012; 2013), por Batista e Carvalho-Silva (2013) e pelo CENPEC (2011), a pedagoga considera que a rotatividade de professores é "letal para as aprendizagens das crianças", pois, quando o grupo de professores começa a ter domínio das propostas pedagógicas desenvolvidas na escola, a equipe acaba se desfazendo por causa das alterações no processo de designação. Ela se queixou do fato de receber, constantemente, professores recém-formados, e daqueles que, apesar de terem uma longa trajetória em outras escolas da rede municipal, não sabem alfabetizar e não estão habituados a uma rotina de estudos.

No enfrentamento dos problemas que resultam da rotatividade de professores na escola, a pedagoga afirmava que sua rigidez na organização do trabalho "causa muito amor, mas causa muita dor", porque, ao mesmo tempo em que ensina e ajuda as professoras, é muito exigente e cobra a aplicação do que foi ensinado. Ao sondar os conhecimentos prévios dos professores, 
sejam eles experientes ou não, ela apresenta o que deviam estudar e aprender. É nesse momento que, segundo a pedagoga, começavam os conflitos e alguns professores desistem do cargo.

Entretanto, embora a rotatividade de professores seja frequente na Escola Municipal Professora Laura Fabri, um aspecto que parece contribuir positivamente com os resultados de aprendizagem é o fato de uma mesma pedagoga, com larga experiência profissional, coordenar os trabalhos da escola há 10 anos e algumas alfabetizadoras também estarem na escola há muito tempo.

A pedagoga também revelou que acompanhava, com assiduidade, o planejamento e as práticas de sala de aula dos recém-chegados. Se ela observava que esse professor não estava se esforçando para avançar, encaminhava o caso para a direção da escola em reuniões da equipe gestora, e, depois de esgotadas todas as ações para melhorar a prática do professor, ele era desligado. A demissão era feita quando o docente não correspondia ao padrão de exigência da escola.

O parâmetro de qualidade docente da escola investigada corresponde à dedicação docente, à responsabilidade e ao empenho para desenvolver a aprendizagem, citados por Alves e Franco (2008) nas pesquisas nacionais. Tais práticas também envolvem a qualidade de planejamento das aulas, entusiasmo, capacidade de avaliação dos registros dos alunos, uso adequado do tempo e organização eficaz da sala de aula, aspectos apontados nos estudos internacionais como características de professores das escolas eficazes (BROOKOVER et al., 1978; MORTIMORE et al., 1988; RUTTTER et al., 1979).

\section{Considerações finais}

Quando considerados os fatores externos, o sucesso escolar se configura na capacidade de a escola produzir resultados acima do esperado (TORRECILLA, 2003). Assim, o sucesso de escolas, como no caso da Escola Municipal Professora Laura Fabri, que alcançou desempenho superior em alfabetização no PROALFA, quando comparado às escolas que não estão situadas em território vulnerável, indica que, embora a vulnerabilidade do território exerça influência sobre as oportunidades educativas oferecidas pela escola, ela não o determina.

A pesquisa revelou que a atuação dos profissionais na escola, sob a coordenação da pedagoga, ameniza o impacto da vulnerabilidade do território e da infraestrutura precária, e que a formação continuada desenvolvida pela pedagoga na escola atua como uma forte estratégia em relação à rotatividade de professores. 
O caso da Escola Municipal Professora Laura Fabri demonstra que a escola que o aluno estuda faz a diferença na aprendizagem. Embora muitas famílias não tenham forte envolvimento com as ações escolares, e a infraestrutura e os equipamentos da escola sejam precários, estes são fatores que influenciam, mas não determinam os resultados de aprendizagem. A organização, a coordenação das práticas de alfabetização e o trabalho coletivo tiveram maior efeito que os aspectos sociais, econômicos e culturais do contexto social em que a escola está inserida e suas limitadas condições de trabalho.

A longa experiência profissional da pedagoga em classes de alfabetização, sua dedicação na coordenação dos trabalhos, seu compromisso com a formação continuada dos professores e seu embasamento teórico são diferenciais citados nas entrevistas realizadas com as professoras e com a diretora, que contribuem positivamente para a aprendizagem dos alunos da escola investigada.

Nos limites da pesquisa realizada, foi possível conhecer alguns fatores que ajudaram a compreender as razões do improvável sucesso em alfabetização da Escola Municipal Professora Laura Fabri, alguns deles já citados em estudos internacionais e nacionais. No entanto, há novas preocupações com o futuro, no âmbito nacional, e que podem influenciar as práticas educativas das escolas.

\section{Referências}

ALVES, M. T. G.; FRANCO, C. A pesquisa em eficácia escolar no Brasil: evidências sobre o efeito das escolas e fatores associados à eficácia escolar. In: BROOKE, N.; SOARES, J. F. (eds.). Pesquisa em eficácia escolar: origem e trajetórias. Belo Horizonte: Editora UFMG, 2008, p. 482-500.

BATISTA, A.; PADILHA, F.; CARVALHO SILVA, H. H. de; ALVES, L.; RIBEIRO V. A escola em contextos de vulnerabilidade social. Salto para o Futuro, Ano XXIII, Boletim 22, nov. 2013. $32 \mathrm{p}$.

BATISTA, A.; PADILHA, F.; CARVALHO SILVA, H. H. de; ALVES, L.; RIBEIRO V. A escola, a metrópole e a vizinhança vulnerável. Cadernos de Pesquisa, São Paulo, Fundação Carlos Chagas, v. 42, n. 146, p. 16-26, mai./ago. 2012.

BATISTA, A. A.; CARVALHO-SILVA, H. Familia, escola, território vulnerável. São Paulo: Cenpec, 2013. 236 p.

BRESSOUX, P. As pesquisas sobre o efeito-escola e o efeito professor. Educação em revista, Belo Horizonte, n. 38, p. 17-88, dez. 2003.

BROOKE, N.; SOARES, F. J. Pesquisa em eficácia escola: origem e trajetórias. Belo Horizonte: UFMG, 2008. 552 p. 
BROOKOVER, W. B.; SCHWEITZER, J. H.; SCHNEIDER, J. M.; BEADY, C. H.; FLOOD, P. K.; WISENBAKER, J. M. Elementary school social climate and school achievement. American Educational Research Journal, v. 15, n. 2, p. 301-318, 1978. In: BROOKE, N.; SOARES, F. J. Pesquisa em eficácia escolar: origem e trajetórias. Belo Horizonte: UFMG, 2008.

CENPEC. Centro de Estudos e Pesquisas em Educação, Cultura e Ação Comunitária. Educação em territórios de alta vulnerabilidade social na metrópole. São Paulo: CENPEC, 2011. 33 p. (Pesquisa)

CONSELHO CONSULTIVO CENTRAL DA EDUCAÇÃO (INGLATERRA). O lar, a escola e a vizinhança. Capítulo 3 (parágrafos 76 a 101) do Relatório de Plowdem. Children and their primary schools. London: HMSO, 1967. In: BROOKE, N.; SOARES, F. J. (orgs.). Pesquisa em eficácia escolar: origem e trajetórias. Belo Horizonte: UFMG, 2008, p. 67-73.

ERNICA, M.; BATISTA, A. A. G. A escola, a metrópole e vizinhança vulnerável. Caderno de pesquisa, v. 42, n. 346, p. 640-666, maio/ago. 2012.

GAUTHIER, C.; BISSONNETTE, S.; RICHARD, M. Ensino explícito e desempenho dos alunos: a gestão dos aprendizados. Petrópolis, RJ: Vozes, 2014. 335 p.

MADAUS, G. F.; AIRASIAN, P. W.; KELLAGHAN, T. Estudos empíricos. In: BROOKE, N.; SOARES, F. J. (orgs.). Pesquisa em eficácia escolar: origem e trajetórias. Belo Horizonte: UFMG, 2008, p. 74-89.

MADAUS, G. F.; AIRASIAN, P. W.; KELLAGHAN, T. Insumos escolares, processos e recursos. In: BROOKE, N.; SOARES, F. J. (orgs.). Pesquisa em eficácia escolar. origem e trajetórias. Belo Horizonte: UFMG, 2008, p. 112-141.

MORTIMORE, P.; SAMMONS, P.; STOLL, L.; LEWIS, D.; ECOB, R. A importância da escola: a necessidade de se considerar as características do alunado? In: BROOKE, N.; SOARES, F. J. (orgs.). Pesquisa em eficácia escolar: origem e trajetórias. Belo Horizonte: UFMG, 2008, p. 187-215.

RUTTER, M.; MAUGHAN, B.; MORTIMORE, P.; OUSTON, J.; SMITH, A. Resultados escolares: frequência, comportamento e desempenho dos alunos. In: BROOKE, N.; SOARES, F. J. (orgs.). Pesquisa em eficácia escolar: origem e trajetórias. Belo Horizonte: UFMG, 2008, p. 163-186.

SOARES, M. Alfabetização: a questão dos métodos. São Paulo: Contexto, 2018. 377 p.

TORRECILLA, F. J. M. Um panorama da pesquisa ibero-americana sobre eficácia escolar. In: BROOKE, N.; SOARES, F. J. (orgs.). Pesquisa em eficácia escolar: origem e trajetórias. Belo Horizonte: UFMG, 2008, p. 466-481.

Recebido em: 20 maio 2019 / Aprovado em: 06 nov. 2019

Cite como

PERPÉTUO, Sandra Maria; COUTRIM, Rosa Maria Exaltação. A coordenação pedagógica faz diferença: As práticas de sucesso em alfabetização em território vulnerável. Dialogia, São Paulo, n. 33, p. 86-98, set./dez. 2019. Disponível em: https://doi.org/10.5585/Dialogia.n33.13925. 